\title{
Changes in nerve function and nerve fibre structure induced by acute, graded compression
}

\section{B RYDEVIK* AND C NORDBORG $\dagger$}

From the Laboratory of Experimental Biology, Department of Anatomy* and Division of Neuropathology, Department of Pathology $\dagger$ University of Göteborg, Göteborg, Sweden

SUMMARY Rabbit tibial nerves were subjected to direct, acute graded compression by means of an inflatable compression chamber. The acute and long term effects of 50, 200 and $400 \mathrm{mmHg}$ applied for two hours on nerve function and nerve fibre structure were investigated. A pressure of $50 \mathrm{mmHg}$ applied for two hours induced only minimal or no acute deterioration of maximal conduction velocity and nerve fibre structure. Conduction velocity was gradually reduced during compression at $200-400 \mathrm{mmHg}$ pressure for two hours and in those cases the recovery of nerve conduction after pressure release was incomplete. Ultrastructural analysis revealed pronounced, early nerve fibre damage in these nerves. Three weeks after compression, nerves compressed at 50 $\mathrm{mmHg}$ for two hours had normal afferent and motor conduction velocity, although there were morphological signs of slight nerve fibre damage. Nerves compressed at $200 \mathrm{mmHg}$ for two hours exhibited reduction of conduction velocity only at the level of compression, in contrast to the nerves compressed at $400 \mathrm{mmHg}$ for two hours in which conduction velocity was reduced both at the level of compression and distal to the compressed segment. Morphologically, the nerves compressed at $200-400 \mathrm{mmHg}$ for two hours showed varying degrees of demyelination and axonal degeneration three weeks after compression.

It is well known that compression of peripheral nerves may induce impairment of nerve function. The clinical picture of a nerve compression lesion depends on several factors, for example the anatomical location of the lesion as well as the severity and duration of the trauma. Acute compression may induce block of conduction which sometimes persists long after the trauma. This phenomenon may occur after, for example, acute trauma to limbs, after compression of the radial nerve against the humerus ("Saturday night palsy") or, more rarely, in association with tourniquet palsy. ${ }^{12}$

The pathophysiology of such acute nerve compression injuries has been studied in several previous experimental investigations. ${ }^{3-11}$ It is often difficult, however, to compare results obtained in the different experimental investigations owing to differences in methods of pressure application and noncomparable pressure levels.

Address for reprint requests: B Rydevik, Laboratory of Experimental Biology, Department of Anatomy, University of Göteborg, P.O. Box 33031, S-400 33 Göteborg, Sweden.

Accepted 20 June 1980
We have tried to overcome some of these problems by using a standardised mode of applying pressure directly to peripheral nerves and then systematically investigating the effects of graded compression on intraneural blood flow, ${ }^{12}$ permeability of intraneural blood vessels and the perineurium ${ }^{13}$ and axonal transport. ${ }^{14}$

The aim of the present investigation was to correlate and compare compression-induced changes in the above-mentioned systems with alterations in nerve function and nerve fibre structure using the same mode of pressure application as previously. Furthermore, the purpose was to investigate the relative importance of mechanical nerve fibre deformation and ischaemia for the functional deterioration of the nerve in association with acute compression of varying magnitude.

\section{Material and methods}

Thirty-seven rabbits of both sexes, weighing $2 \cdot 0$ to $2.5 \mathrm{~kg}$ were used. Anaesthesia was induced by intramuscular injection of $2 \mathrm{ml} / \mathrm{kg}$ bodyweight of Hypnorm (Fluanisone $10 \mathrm{mg}$ and Fentanyl $0.2 \mathrm{mg}$ per 
$\mathrm{ml}$ ). Additional doses of Hypnorm were given when necessary to maintain a sufficient depth of anaesthesia.

Compression procedure. The tibial nerve was exposed between the knee and the ankle by a medial incision of the skin and fascia. This nerve is multifascicular and it contains both sensory and motor fibres. The nerve was compressed by a specially designed compression chamber, previously described in detail.13 This compression device comprises two symmetrical halves of plexi-glass, onto which thin rubber membranes are glued. The two halves were placed around the nerve trunk and secured in position by four small screws. The compression chamber was then connected to a special pressure air system* allowing inflation of the rubber cuffs in the chamber with air of known and desired pressure. The system automatically compensates for any leakage of air, and thus maintains the pressure at a constant level. The length of the compressed nerve segment was $10 \mathrm{~mm}$. The nerves were subjected to compression for two hours at three different pressure levels: 50 $\mathrm{mmHg}, 200 \mathrm{mmHg}$ and $400 \mathrm{mmHg}(1 \mathrm{mmHg}=133 \cdot 4$ Pascal.)

\section{A NERVE FUNCTION}

1 Deterioration of nerve function during compression and early recovery $(n=17)$ After the nerve trunk had been exposed, stimulating and recording electrodes were applied to the nerve in order to record ascending nerve action potentials (NAP) (fig 1a). The stimulating impulses were delivered by a Grass SD 9 stimulator through biopolar J-shaped silver electrodes, which were carefully placed around the nerve distally in the limb, $1 \mathrm{~cm}$ apart, the cathode being most proximal. Recordings were performed by a silver electrode placed around the nerve at the level of the knee and with a remote electrode in the subcutaneous tissue in the thigh. The distance between the stimulating and recording electrodes (usually 50 to $60 \mathrm{~mm}$ ) was kept constant throughout each experiment. The recorded signal was led through a Grass P 18 differential preamplifier to a Tektronix $5103 \mathrm{~N}$ dual-beam storage oscilloscope, equipped with a $5 \mathrm{~A} 15 \mathrm{~N}$ amplifier. The animal and the equipment were grounded. Photographic recordings of the tracings were made with a Polaroid CR 9 camera. The nerve was stimulated with a supramaximal stimulus during the recordings (twice the strength necessary to achieve maximal amplitude of the compound action potential). The duration of the stimulating impulses was $0.1 \mathrm{~ms}$, and impulses were given at a frequency of about $1 \mathrm{~Hz}$ during the recordings. The experiments started with determination of precompression values of the latency until first peak of the recorded compound action potential and the maximal amplitude of this peak of the action potential. The compression chamber was then applied to the nerve. In order to keep the preparation at a constant humidity, the whole wound was covered by

*AB Stille-Werner, P.O. Box 43051, S-10072 Stockholm, Sweden. a thin film of polyethylene. The animal was placed in insulating cushions in order to keep body temperature constant. A heating lamp was placed over the experimental limb and adjusted to keep the temperature close to the nerves at 37 to $38^{\circ} \mathrm{C}$, as measured by a thermistor.

The possible effects of the chamber application per se on impulse conduction velocity and action potential amplitude were studied in experiments in which the chamber was applied around the nerve but not inflated with air (sham experiments, $n=4$ ). The effects of compression were investigated in three series of experiments, at $50 \mathrm{mmHg}(\mathrm{n}=4), 200$ $\mathrm{mmHg}(\mathrm{n}=4)$ and $400 \mathrm{mmHg}(\mathrm{n}=5)$. Compression was maintained for two hours in all experiments. Immediately after the end of the compression period, the chamber was removed from the nerve, but the stimulating and recording electrodes were left in position and nerve function was studied during a twohour recovery period.

Recordings were performed at least every five minutes during compression and also during the recovery period. The fastest conducting fibres of the nerve trunk are the fibres most susceptible to compression trauma. ${ }^{5}$ Thus, changes in the conduction velocity of the fastest fibres, that is, the "maximal conduction velocity of the nerve", compared to precompression values were calculated. Since the conduction distance was kept constant throughout each experiment, conduction velocity changes were obtained by measuring alterations in latency from the stimulus artefact to the first peak of the compound action potential. Action potential amplitude was measured as the height of the first peak, which is most likely to represent the fastest fibres in this triphasic recording system. The conduction velocity and action potential amplitude at each point of time was expressed as per cent of initial, precompression values, which were regarded as $100 \%$. Some of the

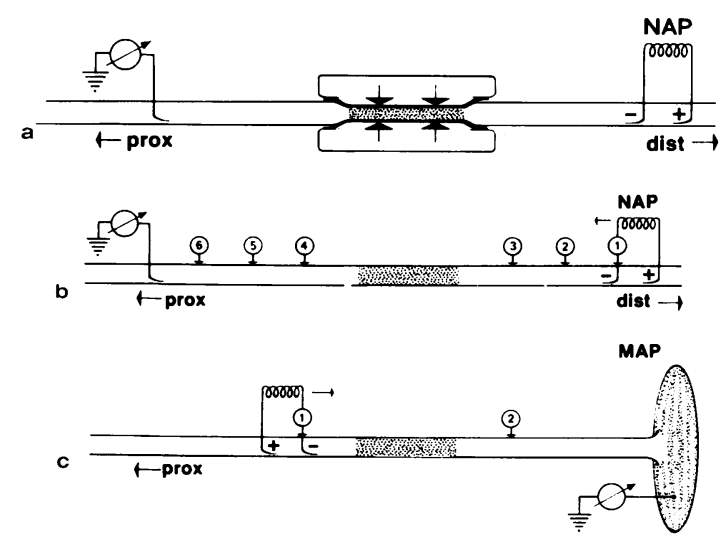

Fig 1 Experimental set-up for studying deterioration of nerve function during $(a)$ and after $(b, c)$ compression. For details see text. 
nerves were subjected to morphological analysis, nerve specimens being removed and processed as described below (see B Nerve structure).

In order to obtain reference values for normal conduction velocity in the rabbit tibial nerve, we investigated the conduction velocity of the right and left nerves in a special group of four control animals. It was found that the conduction velocity of the right nerves was on average $65.5 \pm 2.7$ (SEM) $\mathrm{m} / \mathrm{s}$ and that of the left nerves $66 \cdot 2 \pm 3 \cdot 1 \mathrm{~m} / \mathrm{s}$. The close relation between the velocities recorded in the two nerves was interpreted as evidence that the method of measuring conduction velocity is accurate. This finding also justifies the use of the contralateral nerve as control to the compressed nerves.

2 Late effects of compression on nerve function $(n=18)$ In this series of experiments, nerves were compressed under aseptic conditions, using the previously mentioned compression chamber. The compression time was two hours in all experiments, and the pressure level were the same as in the acute experiments, that is $50 \mathrm{mmHg}(\mathrm{n}=5), 200 \mathrm{mmHg}$ $(n=6)$, and $400 \mathrm{mmHg}(n=7)$ (see also nerve structure, late effects). After compression, fascia and skin were sutured and the animals allowed to recover from the anaesthesia. Three weeks later the animals were anaesthetised again and the nerves reexposed and nerve function studied. The maximal conduction velocity of both the fastest fibres of the whole nerve and motor conduction velocity were investigated in each animal. This was done by measuring both ascending nerve action potentials (NAP) and motor action potentials (MAP) in the abductor hallucis brevis muscle in the foot (fig $1 \mathrm{~b}$, c). NAP was registered by placing the recording electrodes at the level of the knee, as described above. The nerve was then stimulated supramaximally at various points in relation to the compressed nerve segment. The cathode was placed in different, defined positions along the nerve, called positions 1 to 6 , as shown in fig $1 \mathrm{~b}$. The distance between two adjacent cathode positions was $5 \mathrm{~mm}$, except between cathode positions 3 and 4 (see fig 1b) which were on either side of the compressed segment, 20 $\mathrm{mm}$ apart. Thus, the nerve was stimulated at three points distal to the compression, and at three points proximal to the compression. The latency between the start of the stimulus artefact and the first deflection of the recorded compound action potential was measured for each position of the cathode. Each latency value (ms) was plotted against the distance $(\mathrm{mm})$ between the cathode and the recording electrode (see fig 5). It was thus possible to determine the conduction velocity of the nerve segments distal to the compression (between positions 1 and 3 ), over the compressed segment (between positions 3 and 4), proximal to the compression (between positions 4 and 6) and for the whole nerve on average (between positions 1 and 6 ).

Evoked muscle action potentials (MAP) were recorded from the abductor hallucis brevis muscle by means of a needle electrode inserted close to the muscle belly (fig 1c). A remote electrode was placed subcutaneously near the calcaneus. The nerve was stimulated by the bipolar electrodes, the cathode being most distal in these cases. The stimulating electrodes were placed in one position proximal and in one position distal to the compressed segment. Calculation of the latency was performed as described for the NAP-recordings, thus demonstrating the conduction velocity for motor fibres over the compressed nerve segment.

\section{B NERVE FIBRE STRUCTURE}

1 Acute effects (light and electron microscopy) $(n=10)$ The material comprised altogether 10 compressed nerves and their controls. Three nerves were compressed at 50, four at 200 and three at 400 $\mathrm{mmHg}$.

After the neurophysiological recordings had been performed, the exposed part of the nerve was fixed in situ by immersion in a solution containing $10 \%$ paraformaldehyde and $1.25 \%$ purified glutaraldehyde in $0.2 \mathrm{M}$ cacodylate buffer at $\mathrm{pH} 7 \cdot 15$ with added $\mathrm{CaCl}_{2}{ }^{15}$ After one hour the compressed nerve segment, together with the adjacent two to three centimetres on either side, was fixed by ligatures to a wooden peg, excised and placed in the same fixative for another hour. Thereafter, the nerve was fixed in a solution with four times the above-mentioned concentrations of aldehydes for 24 hours at $+4^{\circ} \mathrm{C}$. Specimens were collected from several sites that is proximal to the compressed segment, the proximal edge of the compressed segment, the central part and the distal edge zone, and distal to the compression. After being carefully rinsed in cacodylate buffer, the pieces were post-fixed in $1 \% \mathrm{OsO}_{4}$ for two hours, dehydrated and embedded in Epon 812. One $\mu$ thick longitudinal sections from the different segments were cut on an LKB ultrotome and stained for light microscopy with methylene blue and Azur II. 16 Control specimens were obtained from the corresponding part of the contralateral, not previously exposed, tibial nerve and processed in the same way. All sections were coded. Electron microscopy was performed on specimens from the proximal and distal edge zones in three nerves compressed at 50, 200 and $400 \mathrm{mmHg}$, respectively. About $500 \AA$ thick longitudinal and transverse sections were cut on the same ultrotome and stained with uranyl acetate and lead citrate. The stained sections were then examined under a Philips EM 200 electron microscope.

2 Late effects (light microscopy) $(n=20)$ The material was the same as presented above in the functional test of nerves three weeks after compression but also included two nerves that were not subjected to neurophysiological recordings.

Longitudinal sections from the proximal and distal cuff edge zones, the central part of the compressed segment and from $1 \mathrm{~cm}$ distal to the cuff were examined by light microscopy, together with longitudinal sections from the corresponding parts of the 
contralateral tibial nerve. The histotechnical methods were identical to those in the study of acute effects. An unbiased examination of coded preparations was performed using a five-point scale:

$$
\begin{array}{cc}
0: \quad \begin{array}{c}
\text { no detectable changes of nerve fibre } \\
\text { structure. }
\end{array} \\
+: \quad \begin{array}{c}
\text { occasional nerve fibres showing demyelin- } \\
\text { ation or axonal degeneration. }
\end{array} \\
++: \begin{array}{c}
\text { significant number, but less than } 30 \%, \\
\text { of nerve fibres showing such changes. } \\
\text { more than } 30 \% \text { of nerve fibres showing } \\
\text { such changes, but still a significant } \\
\text { number of histologically intact fibres. } \\
++
\end{array} \\
\begin{array}{c}
\text { only occasional histologically intact nerve } \\
\text { fibres. }
\end{array}
\end{array}
$$

Transverse sections were cut from specimens from the central part of the compressed segments and about $1 \mathrm{~cm}$ distal to the cuff. These sections werc coded and examined with respect to loss of light microscopically visible myelinated nerve fibres. A four-point scale was used for registration.

$$
\begin{aligned}
0: & \text { no loss of nerve fibres } \\
+: & \text { slight loss } \\
++: & \text { moderate loss } \\
+++: & \text { marked loss }
\end{aligned}
$$

\section{Statistical methods}

For comparisons between two groups of observations Wilcoxon's ranking test was used. P-values less than 0.05 were considered significant.

\section{Results}

\section{A NFRVE FUNCTION}

1 Deterioration of nerve function during compression and early recovery $(n=17)$ The mean values of conduction velocity and action potential amplitude obtained in each group of experiments during the two hours of compression and the two hour recovery periods are summarised in figs 2 and 3. A systematic description of the findings at each pressure level is given below.

Sham-experiments $(n=4)$ Conduction velocity remained unaffected throughout the two hour chamber application period, as well as during the two hours following removal of the compression device (fig 2). The action potential amplitude was, however, reduced to about $85 \%$ of its initial value during chamber application (fig 3), and this reduction remained unchanged during the two hour recovery period.

$50 \mathrm{mmHg}-2$ hours $(n=4)$ Conduction velocity was unaffected during the first 30 minutes of compression, after which it decreased to about $95 \%$ of the pre-compression value (fig 2). This slight reduction persisted throughout compres-

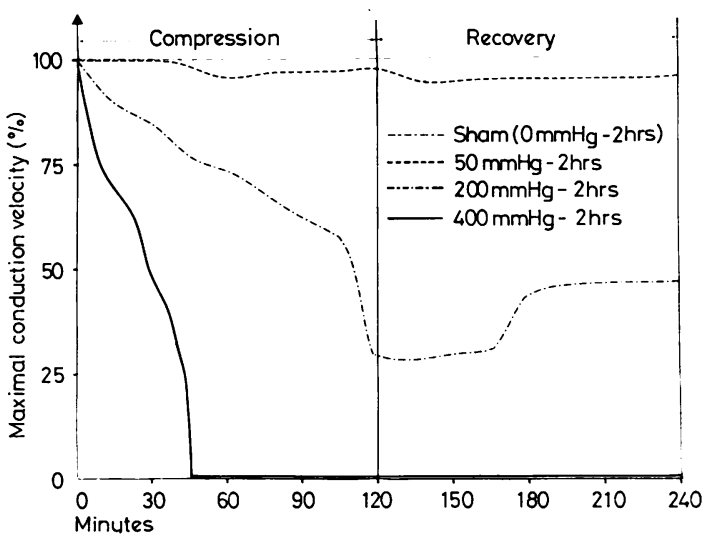

Fig 2 Deterioration of maximal conduction velocity during compression and recovery during the first $2 \mathrm{~h}$ after release of pressure.

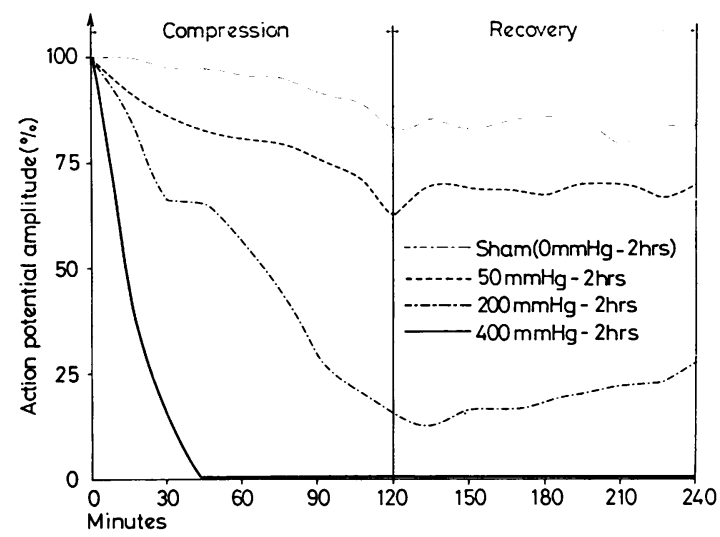

Fig 3 Deterioration of action potential amplitude during compression and recovery during the first $2 \mathrm{~h}$ after pressure release.

sion as well as during the recovery period. The amplitude of the action potential was gradually decreased during compression to about $70 \%$ of pre-compression value and remained at this level during the two hour recovery period (fig 3 ).

$200 \mathrm{mmHg}-2$ hours $(n=4)$ Conduction velocity started to decrease within a few minutes after onset of compression. In two of the nerves, conduction was completely blocked after 110 and 120 minutes respectively. One nerve exhibited a reduction of velocity to about $60 \%$ and the amplitude was $10 \%$ at the end of the two hour compression period. Following pressure release there was, however, in this nerve a continuing decrease of velocity down to zero (fig 4). The fourth nerve in this series was not completely blocked at any time during the experiment. 

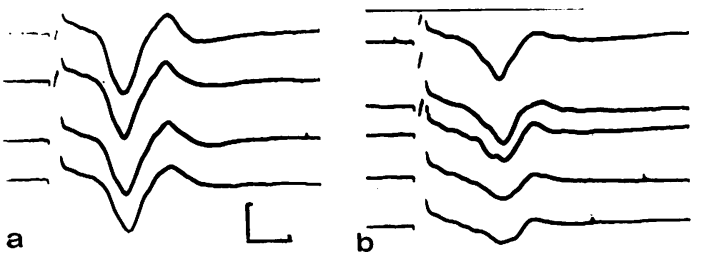

Fig 4 Deterioration of nerve conduction during compression at $200 \mathrm{mmHg}$. (a) Recordings made (from top to bottom) at 75, 80,85 and $95 \mathrm{~min}$ after pressure application. Note decrease of action potential amplitude and increase of latency. (b) Recordings from the same nerve. Two upper sweeps were recorded after 115 and 120 min compression, respectively. Thereafter pressure was released. The following three recordings were made 15,45 and $60 \mathrm{~s}$ after pressure release, respectively. Note that action potential amplitude decreases and latency increases even after pressure release. Amplitude marker: $100 \mu \mathrm{V}$. Time marker: $0.5 \mathrm{~ms}$.

Therefore, mean value of conduction velocity and action potential amplitude of the four nerves (figs 2 and 3 ) did not reach zero at any time.

On an average, the conduction velocity was reduced to about $30 \%$ of its initial value at the end of the compression period, and recovered slightly during the following two hours, to about $45 \%$ of pre-compression values. The amplitude of the action potential was also gradually reduced during compression down to about $15 \%$ of its pre-compression level. There was on average a slight recovery of amplitude, up to about $25 \%$ of the pre-compression value within two hours after compression.

$400 \mathrm{mmHg}-2$ hours $(n=5)$ Conduction velocity began to decrease within the first minute after the start of compression and the reduction then continued rapidly (fig 2 ). The velocity was reduced to about $50 \%$ of its initial value after about 30 minutes' compression and the conduction was completely blocked in all nerves after on average 45 minutes' compression at this pressure level (range: $25-52 \cdot 5 \mathrm{~min}$ ). The amplitude was reduced in a corresponding pattern and also reached zero values after about 45 minutes' compression (fig 3). There was no recovery of nerve function during the two hours following release of the compression.

2 Late effects of compression on nerve function $(n=18)$ The findings three weeks after compression in each group of experiments are summarised in tables 1,2 and 3 and in fig 5a, b. The main findings are described below.

$50 \mathrm{mmHg}-2$ hours $/ 3$ weeks recovery $(n=5)$ (a) NAP: In this series there was no statisti-
Table $150 \mathrm{mmHg}-2$ hours/3 weeks recovery. Conduction velocity $N A P(\mathrm{~m} / \mathrm{s})$. Proximal to compressed segment (positions 4-6). Over compressed segment (positions 3-4). Distal to compressed segment (positions 1-3)

\begin{tabular}{|c|c|c|c|c|c|}
\hline $\begin{array}{l}\text { Rabbit } \\
\text { number }\end{array}$ & $\begin{array}{l}\text { Prox } \\
4-6\end{array}$ & $\underset{3-4}{\text { Compr }}$ & $\begin{array}{l}\text { Dist } \\
1-3\end{array}$ & $1-6$ & Control \\
\hline $\begin{array}{l}1 \\
2 \\
3 \\
4 \\
5 \\
\text { Mean } \\
\text { SEM }\end{array}$ & $\begin{array}{r}76.9 \\
71 \cdot 4 \\
64.5 \\
66 \cdot 7 \\
62 \cdot 5 \\
68.4 \\
2.6\end{array}$ & $\begin{array}{r}71 \cdot 4 \\
71 \cdot 4 \\
64 \cdot 5 \\
66 \cdot 7 \\
62 \cdot 5 \\
67 \cdot 3 \\
1 \cdot 8\end{array}$ & $\begin{array}{r}76 \cdot 9 \\
71 \cdot 4 \\
64 \cdot 5 \\
66 \cdot 7 \\
62 \cdot 5 \\
68 \cdot 4 \\
2 \cdot 6\end{array}$ & $\begin{array}{r}74 \cdot 1 \\
71 \cdot 4 \\
64 \cdot 5 \\
66 \cdot 7 \\
62 \cdot 5 \\
67 \cdot 8 \\
2 \cdot 1\end{array}$ & $\begin{array}{r}75 \cdot 0 \\
72 \cdot 6 \\
65 \cdot 7 \\
66 \cdot 7 \\
61 \cdot 3 \\
68 \cdot 3 \\
2 \cdot 5\end{array}$ \\
\hline
\end{tabular}

Table $2200 \mathrm{mmHg}-2$ hours $/ 3$ weeks recovery Conduction velocity NAP $(\mathrm{m} / \mathrm{s})$. Proximal to compressed segment (positions 4-6), Over compressed segment (positions 3-4), Distal to compressed segment (positions 1-3)

\begin{tabular}{|c|c|c|c|c|c|}
\hline $\begin{array}{l}\text { Rabbit } \\
\text { number }\end{array}$ & $\begin{array}{l}\text { Prox } \\
4-6\end{array}$ & $\begin{array}{l}\text { Compr } \\
3-4\end{array}$ & $\begin{array}{l}\text { Dist } \\
1-3\end{array}$ & $1-6$ & Control \\
\hline $\begin{array}{c}6 \\
7 \\
8 \\
9 \\
10 \\
11 \\
\text { Mean } \\
\text { SEM }\end{array}$ & $\begin{array}{r}69 \cdot 0 \\
56 \cdot 0 \\
66 \cdot 7 \\
58 \cdot 8 \\
58 \cdot 8 \\
66 \cdot 7 \\
62 \cdot 7 \\
2 \cdot 2\end{array}$ & $\begin{array}{r}48 \cdot 8 \\
32 \cdot 6 \\
45 \cdot 4 \\
37 \cdot 7 \\
29 \cdot 9 \\
48 \cdot 8 \\
40 \cdot 6 \\
3 \cdot 5\end{array}$ & $\begin{array}{r}83 \cdot 3 \\
53 \cdot 8 \\
50 \cdot 0 \\
58 \cdot 8 \\
50 \cdot 0 \\
62 \cdot 5 \\
59 \cdot 7 \\
5 \cdot 1\end{array}$ & $\begin{array}{r}59 \cdot 3 \\
45 \cdot 0 \\
50 \cdot 6 \\
46 \cdot 0 \\
38 \cdot 5 \\
55 \cdot 6 \\
49 \cdot 2 \\
2 \cdot 1\end{array}$ & $\begin{array}{r}83 \cdot 3 \\
68 \cdot 2 \\
62 \cdot 5 \\
71 \cdot 4 \\
62 \cdot 5 \\
66 \cdot 7 \\
69 \cdot 1 \\
3 \cdot 2\end{array}$ \\
\hline
\end{tabular}

Table $3400 \mathrm{mmHg}-2$ hours/3 weeks recovery. Conduction velocity $N A P(\mathrm{~m} / \mathrm{s})$. Proximal to compressed segment (positions 4-6). Over compressed segment (positions 3-4) Distal to compressed segment (positions 1-3)

\begin{tabular}{llllll}
\hline $\begin{array}{l}\text { Rabbit } \\
\text { number }\end{array}$ & $\begin{array}{l}\text { Prox } \\
4-6\end{array}$ & $\begin{array}{l}\text { Compr } \\
3-4\end{array}$ & $\begin{array}{l}\text { Dist } \\
1-3\end{array}$ & $1-6$ & Control \\
\hline 12 & $62 \cdot 5$ & $38 \cdot 8$ & $41 \cdot 7$ & $43 \cdot 4$ & $62 \cdot 5$ \\
13 & $47 \cdot 6$ & $39 \cdot 2$ & $47 \cdot 6$ & $43 \cdot 0$ & $71 \cdot 4$ \\
14 & $59 \cdot 3$ & $31 \cdot 5$ & $32 \cdot 3$ & $35 \cdot 2$ & - \\
15 & $58 \cdot 8$ & $28 \cdot 2$ & $51 \cdot 7$ & $38 \cdot 1$ & $58 \cdot 8$ \\
16 & $66 \cdot 6$ & $31 \cdot 3$ & $52 \cdot 6$ & $40 \cdot 8$ & $71 \cdot 4$ \\
17 & $55 \cdot 5$ & $37 \cdot 0$ & $23 \cdot 2$ & $35 \cdot 0$ & $55 \cdot 6$ \\
18 & $47 \cdot 6$ & $0 \cdot 0$ & $0 \cdot 0$ & $0 \cdot 0$ & $52 \cdot 6$ \\
Mean & $56 \cdot 8$ & $29 \cdot 4$ & $35 \cdot 6$ & $33 \cdot 6$ & $62 \cdot 1$ \\
SEM & $2 \cdot 7$ & $5 \cdot 1$ & $7 \cdot 2$ & $5 \cdot 7$ & $3 \cdot 3$ \\
\hline
\end{tabular}

cally significant difference between the conduction velocities of the compressed segment and the segments proximal and distal to this level. Neither was there any difference between the compressed nerves and their controls (table 1). In fact, the conduction velocities of the compressed nerves and their controls were in most cases identical (table 1). There was thus no delayed conduction over the compressed nerve segments.

(b) MAP: Motor conduction velocity over the compressed segment was on average $52 \cdot 8 \pm 2 \cdot 0$ $\mathrm{m} / \mathrm{s}$., which is identical to the mean value of the control nerves $(52 \cdot 8 \pm 2 \cdot 1 \mathrm{~m} / \mathrm{s})$. 


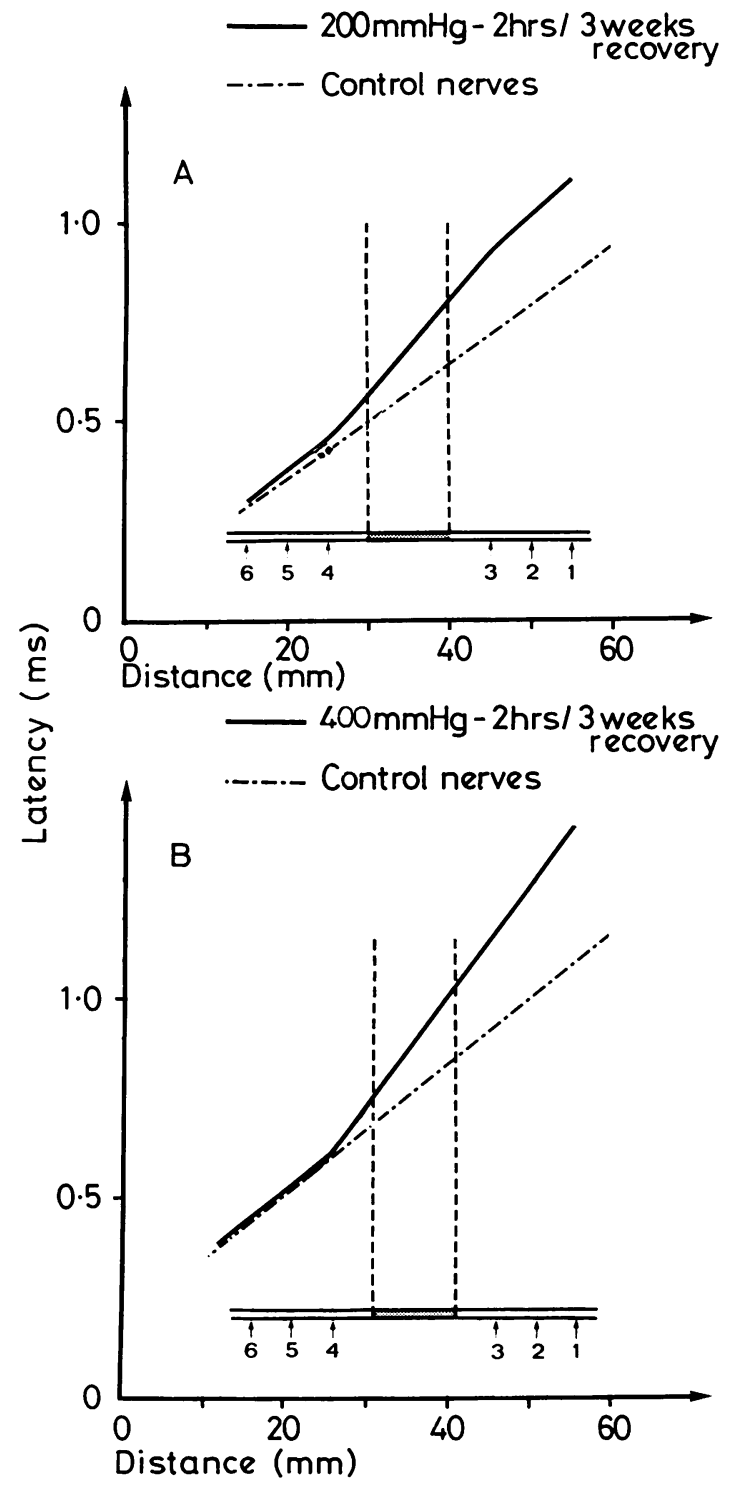

Fig 5a, b Relation between conduction distance and latency for nerve action potential (NAP) 3 weeks after compression. (a) The diagram shows mean values of all nerves compressed at $200 \mathrm{mmHg}$ for $2 \mathrm{~h}$. Arrows indicate the cathode positions 1 to 6 (cf fig $1 b$ ). Compressed segment is shaded. Note localised reduction of conduction velocity over the compressed segment (cf. Table 2). (b) Mean values 3 weeks after compression at $400 \mathrm{mmHg}$ for $2 \mathrm{~h}$. Note that conduction velocity is decreased both at the level of compression and distal to this lorel.
$200 \mathrm{mmHg}-2$ hours $/ 3$ weeks recovery $(n=6)$ (a) NAP: All nerves in this series demonstrated some reduction of conduction velocity over the compressed nerve segment (table 2, fig $5 \mathrm{a})$, but none of the nerves was completely blocked. The average conduction velocity over the compressed segment (cathode positions 3-4) was $40.6 \pm 3.5 \mathrm{~m} / \mathrm{s}$, which is significantly lower than both the velocities of the proximal (cathode positions 4-6:62.7 $\pm 2 \cdot 2 \mathrm{~m} / \mathrm{s}$ ) and the distal (cathode positions $1-3: 59 \cdot 7 \pm 5 \cdot 1 \mathrm{~m} / \mathrm{s}$ ) nerve segments. There was no statistically significant difference, however, between the conduction velocities of the proximal and the distal nerve segments or between the velocity of the control nerves and the velocities of the proximal and distal segments of the compressed nerves (table 2).

(b) MAP: Average motor conduction velocity over the compressed segments was $43 \cdot 8 \pm 3 \cdot 3 \mathrm{~m} / \mathrm{s}$, which is $83 \%$ of the mean value of the conduction velocity of the control nerves $(52.7 \pm 1.8 \mathrm{~m} / \mathrm{s})$. The difference was not satistically significant, however.

$400 \mathrm{mmHg}-2$ hours $/ 3$ weeks recovery $(n=7)$ (a) NAP: There was marked reduction of the conduction velocity over the compressed segments (table 3, cathode positions 3-4: mean 29.4 \pm $5 \cdot 1 \mathrm{~m} / \mathrm{s}$ ), these values being statistically significantly lower than in the proximal segment (cathode position 4-6: mean $56.8 \pm 2.7 \mathrm{~m} / \mathrm{s}$, and in the control nerves $62 \cdot 1 \pm 3.3 \mathrm{~m} / \mathrm{s}$ ). One of the nerves (animal No 18) was completely blocked (fig 6). In this series the conduction velocity of the nerve segment distal to the compression (cathode positions 1-3) was also reduced $(35.6 \pm 7.2 \mathrm{~m} / \mathrm{s}$ ) (table 3 , fig $5 \mathrm{~b}$ ), contrary to in the nerve compressed at $200 \mathrm{mmHg}$ (table 2). In the nerves compressed at $400 \mathrm{mmHg}$ there was no statistically significant difference between the velocities over the compressed segment (mean 29.4 $\pm 5.1 \mathrm{~m} / \mathrm{s}$ ) and the distal segment (mean $35 \cdot 6 \pm 7 \cdot 2 \mathrm{~m} / \mathrm{s}$ ) or between the proximal segment (mean $56.8 \pm 2.7 \mathrm{~m} / \mathrm{s}$ ) and the control nerves (mean $62 \cdot 1 \pm 3 \cdot 3 \mathrm{~m} / \mathrm{s}$ ).

(b) MAP: The average motor conduction velocity over the compressed segment (cathode positions $3-4$ ) was $35.3 \pm 1.7 \mathrm{~m} / \mathrm{s}$, which is $75 \%$ of the velocity of the control nerves $(47 \cdot 2 \pm 3 \cdot 3$ $\mathrm{m} / \mathrm{s}$ ). The difference was statistically significant.

\section{B NERVE FIBRE STRUCTURE}

1 Acute effects This part of the study was performed in order to illustrate what kind of light microscopical and ultrastructural abnormalities that could be found two hours after release of the applied pressure. The material was limited to a 

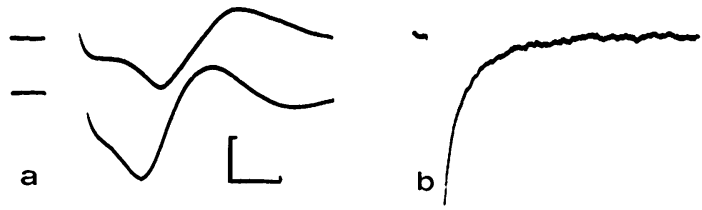

Fig 6 NAP recordings from animal No 18, 3 weeks after compression at $400 \mathrm{mmHg}$ for $2 \mathrm{~h}$. (a) Stimulation at two points proximal to the compressed segment (cathode pos. 4 and 5). (b) Stimulation distal to the compressed segment (cathode pos. 1). There is no NAP propagation through the compressed segment in this nerve, being the only nerve completely blocked at this time. Amplitude marker: $100 \mu \mathrm{V}$. Time marker: 0.2 ms.

few animals and hence the differences between the different groups of nerves were only estimated and not evaluated statistically.

In the nerves subjected to two hours' compression at $50 \mathrm{mmHg}$ no certain abnormality could be seen on light microscopy. Nor were there any obvious ultrastructural abnormalities in the nerve fibres.

All four nerves subjected to $200 \mathrm{mmHg}$ for two hours showed light microscopical changes of varying severity two hours after release of pressure. Longitudinal sections revealed widening of Schmidt-Lanterman incisures, nerve fibre varicosities and complex folding of myelin. In three of the nerves the changes were pronounced, with estimated damage to more than $30 \%$ of the nerve fibres. In one nerve the changes were less pronounced, but still obvious. Electron microscopy was performed on one of the nerves. In transverse sections frequent rupture and coiling back of myelin was seen, which sometimes affected all layers of the myelin sheath. Furthermore, many nerve fibres showed intramyelin spaces, filled with homogeneous or finely particulate material (fig 7a). Longitudinal sections sheath invagination (fig 8a), which together with revealed pictures, suggestive of paranodal myelin the aforementioned changes, is in good agreement with the findings of Ochoa et al. ${ }^{10}$ Some axons of myelinated fibres were shrunken and surrounded by abundant, homogeneous or finely particulate matrix (fig 7a). Many axons contained numerous rounded spaces, presumably representing swollen endoplasmic reticulum and degenerated mitochondria. In some axons there was also an abundance of intact mitochondria and dense bodies. A considerable number of unmyelinated fibres showed marked swelling and intraaxonal changes similar to those of myelinated fibres.

In the three nerves compressed at $400 \mathrm{~mm} \mathrm{Hg}$ for two hours the same kind of light microscopical changes were seen as after $200 \mathrm{mmHg}$. The changes, were, however, judged as more severe, also with pictures suggesting early breaking up of myelin sheaths. Electron microscopy on one of the nerves revealed more severe deteriorations of the same quality as noted after $200 \mathrm{mmHg}$ (figs $7 \mathrm{~b}$ and $8 \mathrm{~b}$ ).

2 Late effects Nerves left in situ for three weeks after compression were examined by light microscopy with special reference to changes in nerve fibres. In longitudinal sections two different phenomena were found, that is signs of demyelination and axonal degeneration. The former was noticed as segments with no visible myelin sheaths or very thin and short internodal segments interposed between thicker and longer segments. As signs of the latter were considered ovoid aggregations of deeply stained, often rounded fragments as described in the literature. ${ }^{17}$ In the transverse sections the loss of myelinated fibres was estimated.

As can be seen in table 4 the presence of nerve fibre damage was slight in longitudinal sections from nerves exposed to $50 \mathrm{mmHg}$ for

Table $450 \mathrm{mmHg}-2$ hours/3 weeks recovery

\begin{tabular}{|c|c|c|c|c|c|c|c|c|}
\hline \multirow{2}{*}{$\begin{array}{l}\text { Rabbit } \\
\text { number }\end{array}$} & \multicolumn{5}{|c|}{ Present nerve fibre injury } & \multicolumn{3}{|c|}{ Loss of myelinated fibres } \\
\hline & $\begin{array}{l}\text { Prox } \\
\text { edge }\end{array}$ & Centre & $\begin{array}{l}\text { Dist } \\
\text { edge }\end{array}$ & $\begin{array}{l}\text { Dist to } \\
\text { compr }\end{array}$ & Control & Centre & $\begin{array}{l}\text { Dist to } \\
\text { compr }\end{array}$ & Control \\
\hline $\begin{array}{l}1 \\
2 \\
3 \\
4 \\
5\end{array}$ & $\begin{array}{l}+ \\
++ \\
0 \\
0 \\
0\end{array}$ & $\begin{array}{l}+ \\
++ \\
0 \\
0 \\
+\end{array}$ & $\begin{array}{l}++ \\
++ \\
++ \\
0 \\
+++\end{array}$ & $\begin{array}{l}0 \\
++ \\
0 \\
0 \\
0\end{array}$ & $\begin{array}{l}+ \\
+ \\
0 \\
0 \\
+\end{array}$ & $\begin{array}{l}0 \\
0 \\
0 \\
0 \\
0\end{array}$ & $\begin{array}{l}0 \\
0 \\
0 \\
0 \\
0\end{array}$ & $\begin{array}{l}0 \\
0 \\
0 \\
0 \\
0\end{array}$ \\
\hline \multicolumn{9}{|c|}{$\begin{array}{rc}\text { Present nerve fibre injury: } & \text { Loss of myelinated fibres: } \\
\text { 0: none } & 0: \text { none } \\
+: \text { single fibres } & +: \text { slight } \\
++: \text { less than } 30 \% \text { of fibres } & ++: \text { moderate } \\
+++: \text { more than } 30 \% \text { of fibres } & +++: \text { marked }\end{array}$} \\
\hline
\end{tabular}




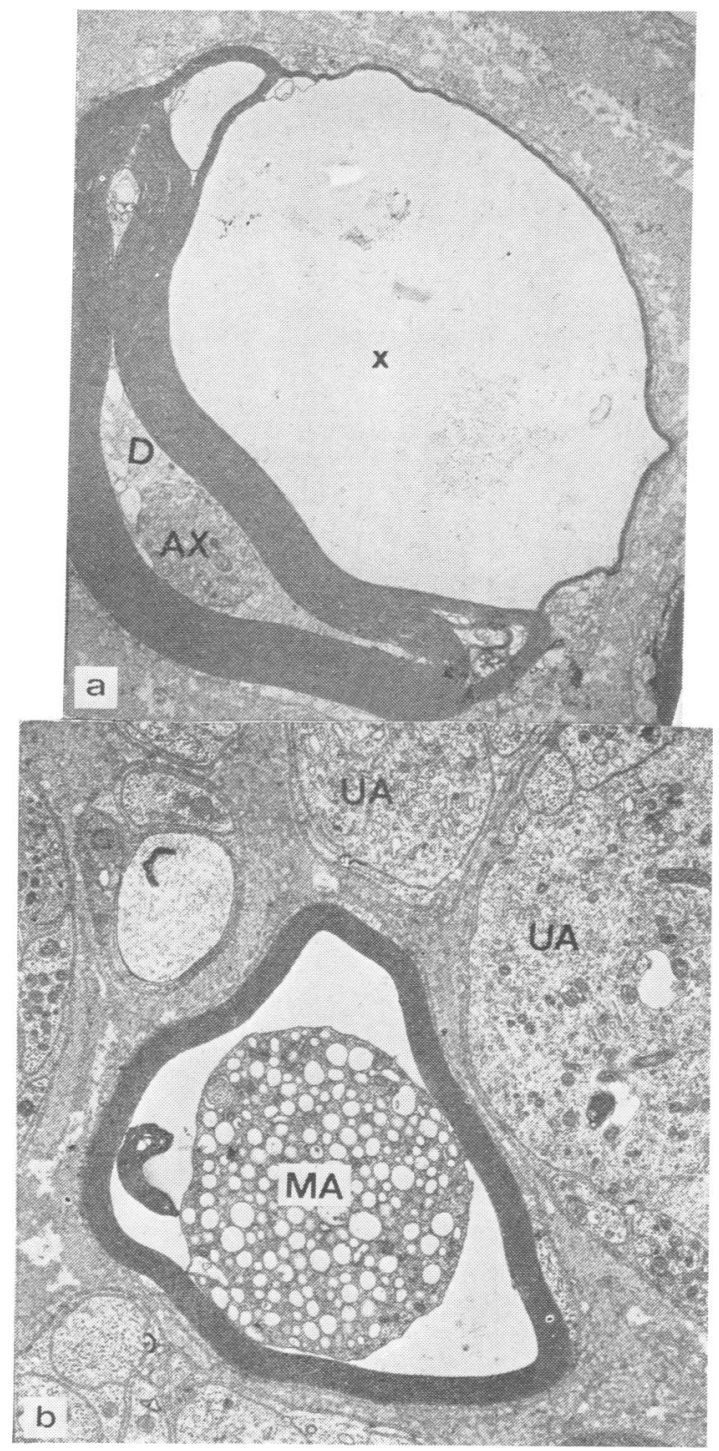

Fig 7 Distal edge zone 2 h after compression.

(a) Compression at $200 \mathrm{mmHg}$ for $2 \mathrm{~h}$. Intramyelin space filled with homogeneous and finely particulate material $(X)$. Shrunken axon $(A X)$ is surrounded by finely particulate material $(D)(\times 5200)$. (b) Compression at $400 \mathrm{mmHg}$ for $2 \mathrm{~h}$. Shrunken myelinated axon (MA) with numerous round spaces. Extreme swelling of unmyelinated axons $(U A)(\times 8600)$.

two hours. In one nerve no changes could be detected. In the other nerves less than $30 \%$ of the nerve fibres were damaged, except for one segment, which showed more severe injury. At this pressure level segmental demyelination domin- ated. In the corresponding control nerves scattered fibres showed segmental demyelination or axonal degeneration. The difference between the compressed nerves and their controls was not statistically significant. There was no detectable loss of myelinated fibres as judged by light microscopical screening of transverse sections.

Table 5 shows the changes in the nerves exposed to $200 \mathrm{~mm} \mathrm{Hg}$ for two hours. The signs of nerve fibre damage were more pronounced in this category than in the previous group. None of the nerves were free from changes. Signs of axonal degenerations as well as demyelination were seen. Three of the controls also showed axonal degeneration and/or demyelination in a few fibres. The difference between the compressed nerves and controls was statistically significant only for the distal edge zone. There was also a slight to moderate loss of myelinated fibres in transverse sections in five out of seven nerves.

Table 6 shows the result from nerves subjected to $400 \mathrm{mmHg}$ for two hours. According to this, the damage as seen in longitudinal sections was more severe than at lower pressure levels. All nerves contained segments with changes in more than $30 \%$ of the fibres. The controls showed a slight to moderate element of degenerative phenomena as did the controls at other pressures. The difference between the compressed nerves and controls was statisticaily significant for all segments of the compressed nerves. Light microscopical screening of transverse sections revealed a slight to marked loss of myelinated fibres in all compressed nerves (fig 9).

\section{Discussion}

Deterioration of nerve function and structure during compression and early recovery The present investigation has demonstrated that graded compression of peripheral nerve may induce acute functional and structural disturbances of varying degree.

Application of the chamber around the nerve without inflation did not influence the maximal conduction velocity (fig 2), but the amplitude was reduced by about $15 \%$ (fig 3), indicating that the function of some fibres was impaired by the sham procedure. The findings during compression at $50 \mathrm{mmHg}$ indicate a largely unaffected nerve conduction, at least in the fastest fibres (figs 2 and 3 ). It has recently been demonstrated, however, using the same mode of pressure application, that $50 \mathrm{mmHg}$ during two hours acutely blocks axonal transport in the rabbit vagus nerve. ${ }^{14}$ Our findings thus indicate a differing susceptibility of axonal 


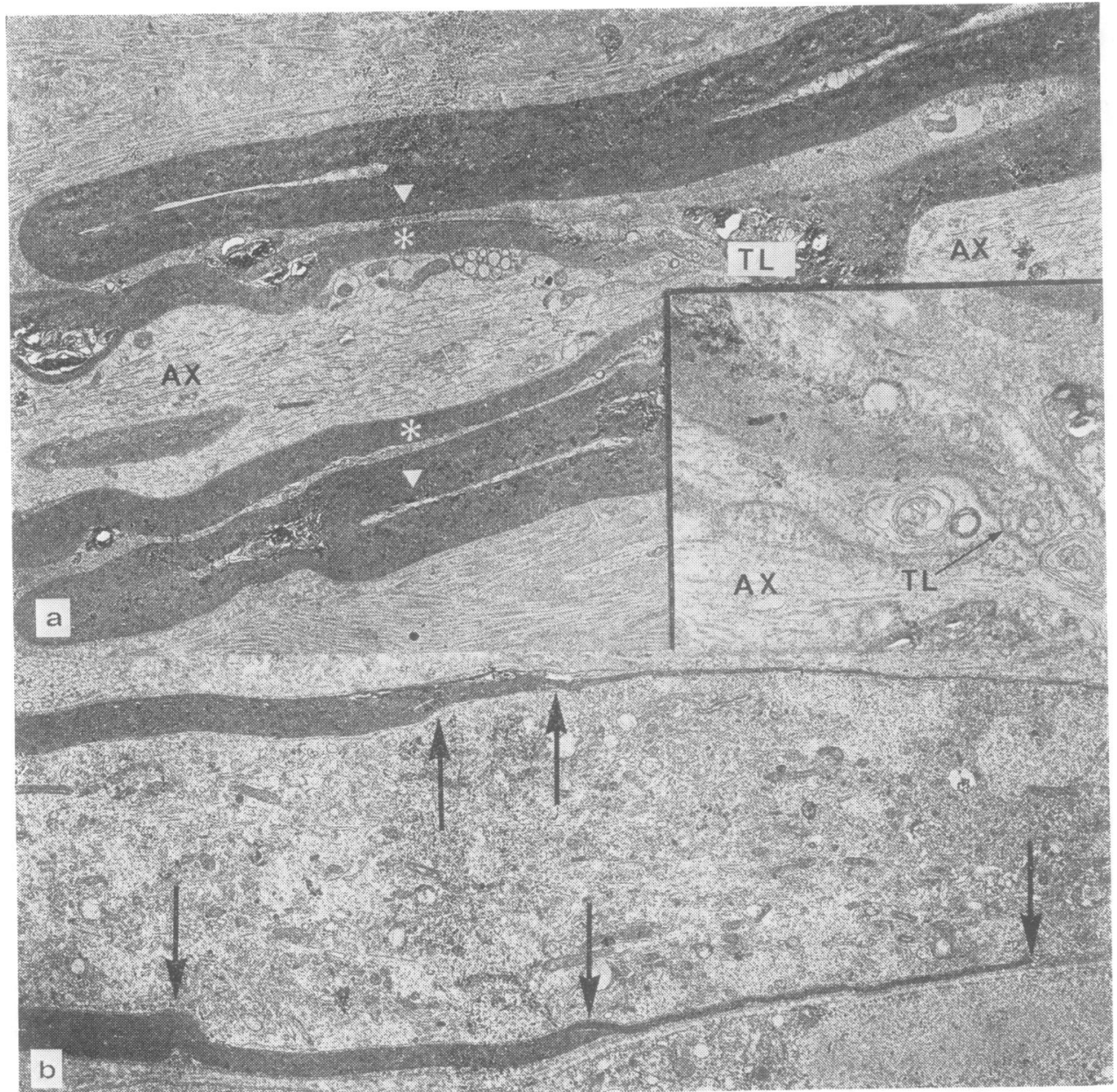

Fig 8 (a) Proximal edge zone $2 \mathrm{~h}$ after compression at $200 \mathrm{mmHg}$ for $2 \mathrm{~h}$. Picture suggestive of paranodal invag ination of myelin. Myelin sheath ending $\left({ }^{*}\right)$, surrounded by thicker folds of the myelin sheath $(\nabla)$ belonging to the adjacent segment. TL: terminal loops of myelin sheath. AX: axon. ( $\times 3600$ and 16200$)$. (b) Proximal edge zone h2 after compression at $400 \mathrm{mmHg}$ for $2 \mathrm{~h}$. Stepwise (arrows) tapering of myelin sheath $(\times 8600)$.

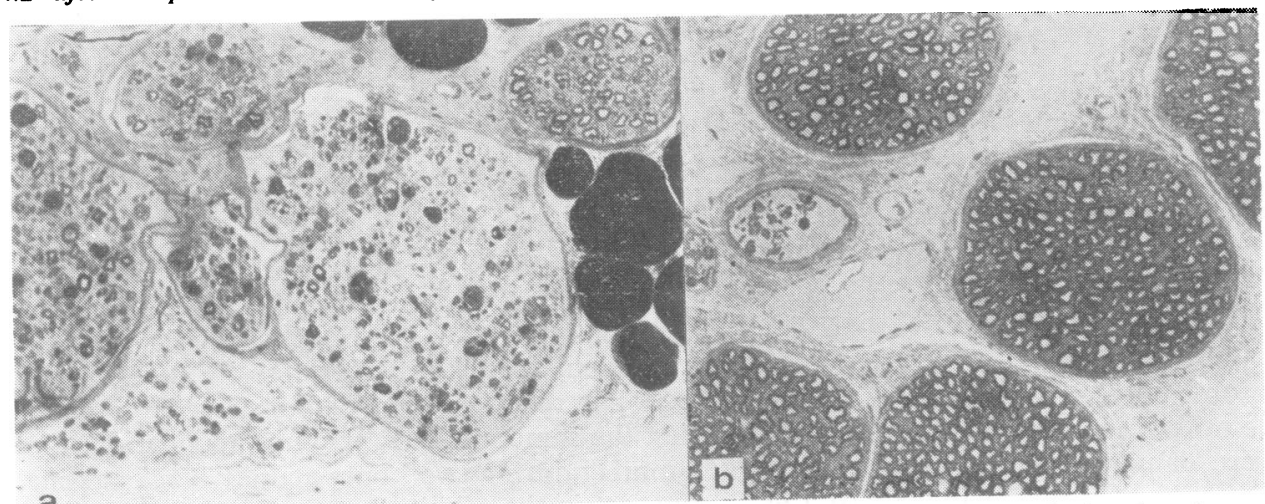

a

Fig 9 (a) 3 weeks after compression at $400 \mathrm{mmHg}$ for $2 \mathrm{~h}$. Nerve fascicles with marked and moderate loss of myelinated fibres $(\times 160)$. (b) Control nerve $(\times 160)$. 
Table $5200 \mathrm{mmHg}-2$ hours/3 weeks recovery

\begin{tabular}{|c|c|c|c|c|c|c|c|c|}
\hline \multirow{2}{*}{$\begin{array}{l}\text { Rabbit } \\
\text { number }\end{array}$} & \multicolumn{5}{|c|}{ Present nerve fibre injury } & \multicolumn{3}{|c|}{ Loss of myelinated fibres } \\
\hline & $\begin{array}{l}P: o x \\
\text { edge }\end{array}$ & Centie & $\begin{array}{l}\text { Dist } \\
\text { edge }\end{array}$ & $\begin{array}{l}\text { Dist to } \\
\text { compr }\end{array}$ & Control & Centre & $\begin{array}{l}\text { Dist to } \\
\text { compr }\end{array}$ & Control \\
\hline 6 & $\rightarrow+$ & ++ & $++t$ & ++ & ++ & $+t$ & $t+$ & 0 \\
\hline 7 & -++ & $+\cdots$ & $\ldots+$ & +1 & $\mp$ & + & + & 0 \\
\hline 8 & $+\div$ & + & $T+T$ & . $\div$ & 0 & 0 & 0 & 0 \\
\hline 9 & $\cdots$ & $+\ldots+$ & ++++ & $++\div$ & 0 & ++ & ++ & 0 \\
\hline 10 & ++ & +1 & -+ & ++ & $\because$ & ++ & +- & 0 \\
\hline 11 & 0 & 0 & $++\cdots$ & 0 & 0 & 0 & 0 & 0 \\
\hline 19 & ++ & $+t$ & ++ & + & 0 & + & 0 & 0 \\
\hline
\end{tabular}

Present nerve fibre injury:

0 : none

+ : single fibres

-: less than $30 \%$ of fibres

: more than $30 \%$ of fibres

+++ : only occasional intact nerve fibres
Loss of myelinated fibres:

$$
0 \text { : none }
$$$$
\text { t-: slight }
$$

++ : moderate

+++ : marked

Table $6400 \mathrm{mmHg}-2$ hours/3 weeks recovery

\begin{tabular}{|c|c|c|c|c|c|c|c|c|}
\hline \multirow{2}{*}{$\begin{array}{l}\text { Rabbit } \\
\text { number }\end{array}$} & \multicolumn{5}{|c|}{ Present nerve fibre injury } & \multicolumn{3}{|c|}{ Loss of myelinated fibres } \\
\hline & $\begin{array}{l}\text { Prox } \\
\text { edge }\end{array}$ & Centre & $\begin{array}{l}\text { Dist } \\
\text { edge }\end{array}$ & $\begin{array}{l}\text { Dist to } \\
\text { compr }\end{array}$ & Control & Centre & $\begin{array}{l}\text { Dist to } \\
\text { compr }\end{array}$ & Control \\
\hline 12 & + & $+t+$ & ++++ & $+t$ & $\div$ & + & + & 0 \\
\hline 13 & +++ & -+++ & ++++ & ++ & +1 & ++ & ++ & 0 \\
\hline 14 & ++ & $+\cdots$ & $+\ldots$ & ++ & 0 & ++ & $T+$ & 0 \\
\hline 15 & $\rightarrow+$ & $+t$ & $+i+$ & +++ & 0 & ++ & ++ & 0 \\
\hline 17 & $\ldots$ & $\cdot \ldots+$ & $+\cdots$ & $+T$ & $\rightarrow$ & ++ & $+\cdots$ & 0 \\
\hline 18 & $-1+$ & $\cdots++$ & $++\cdots$ & $+t+$ & 0 & ++ & +++ & 0 \\
\hline 20 & -+++ & $+\div$ & $+1-+$ & +++ & $+t$ & ++ & $++\cdots$ & 0 \\
\hline
\end{tabular}

Present nerve fibre injury:

0 : none

+ : single fibres

+ : less than $30 \%$ of fibres

+++ : more than $30 \%$ of fibres

++++ : only occasional intact nerve fibres

transport systems and nerve action potential propagation to compression. Both these functions are known to be energy dependent processes. ${ }^{18} 19$ Axonal transport of proteins involves, however, a transfer of material along the nerve fibres, while the propagation of the nerve impulses is merely a process of transfer of ions across the axonal membrane. This suggests that axonal transport may be a more energy-consuming process than impulse propagation, and thus more susceptible to compression and ischaemia. It should be noted that the effect of compression on axonal transport was studied in rabbit vagus nerve ${ }^{14}$ while nerve conduction during compression was studied in the tibial nerve. The monofascicular vagus nerve may well be more susceptible to compression trauma than the multifascicular tibial nerve ${ }^{20}$ but, on the other hand, axonal transport during compression was studied in the small unmyelinated fibres of the vagus nerve, and such fibres are considered to be more resistant to compression trauma and

$$
\begin{gathered}
\text { Loss of myelinated fibres: } \\
\text { 0: none } \\
+: \text { slight } \\
++: \text { moderate } \\
+++: \text { marked }
\end{gathered}
$$

ischaemia than the large diameter nerve fibres studied in the present investigation. ${ }^{10}{ }^{21-23}$

Compression at $200 \mathrm{mmHg}$ induced a gradual decrease of the conduction velocity and action potential amplitude during two hours of compression (fig 2). $200 \mathrm{mmHg}$ is well above the critical value of $60-80 \mathrm{mmHg}$ which has been shown to induce complete ischaemia of the compressed nerve segment in this model. ${ }^{12}$ The present light and electron microscopical findings also indicate pronounced nerve fibre deformation at this pressure level (figs 7 and 8 ). The deterioration of nerve function was nevertheless not as rapid as was demonstrated by Lundborg $^{9}$ when the wholetibial nerve was made ischaemic by a tourniquet around the thigh (fig 10). The segments of the nerve proximal and distal to the compression as well as the tissues in the rest of the limb were normally vascularised in contrast to the tissues in the experiments by Lundborg. ${ }^{9}$ Thus, in our experiments oxygen may diffuse into the com- 


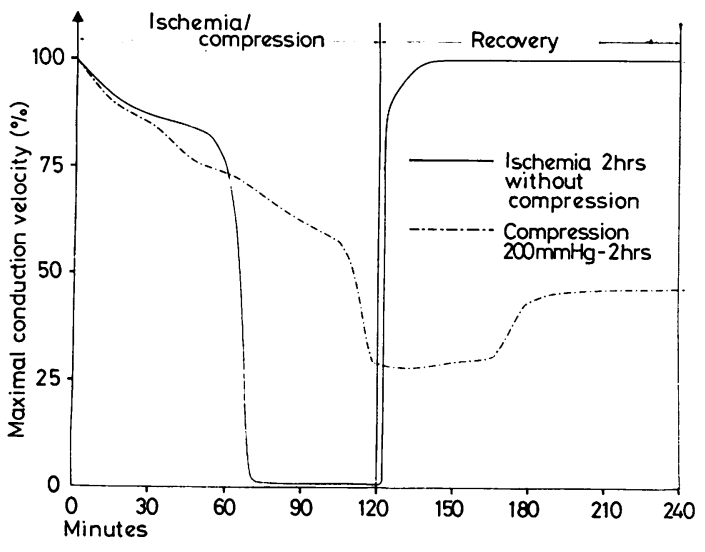

Fig 10 Comparison between the effects on maximal conduction velocity of local compression at $200 \mathrm{mmHg}$ for $2 h$ in the present investigation and of total tourniquet ischaemia of the hind limb without compression of the tibial nerve ${ }^{\vartheta}$. For details see text.

pressed segment from the parts of the nerve proximal and distal to the compression, as suggested by Bentley and Schlapp, ${ }^{6}$ or through the rubber membranes in the compression cuff as demonstrated in tracheal cuffs. ${ }^{24}$ Possibly, sodium and potassium ions invoved in the repolarisation process in the nerve, might diffuse in a similar way from the adjacent normal nerve. A third factor which may support the transmission of impulses through the compressed segment is the known ability of the action potential to pass at least one or two injured internodes, which in the large fibres are more than $1 \mathrm{~mm}$ long. Moreover, in Lundborg's experiments, ${ }^{9}$ the temperature in the ischaemic limb gradually approached room temperature, while we kept the temperature of the nerve at $37-38^{\circ} \mathrm{C}$. This may also be of importance for the differences in functional deterioration.

The slow and incomplete recovery of nerve function after compression at $200 \mathrm{mmHg}$ for two hours as compared to the recovery after two hours of ischaemia without compression (fig 10) is probably due to nerve fibre deformation in the compressed nerves (figs 7 and 8).

Compression at $400 \mathrm{mmHg}$ induced a rapid decrease of nerve function and the conduction was completely blocked after on an average 45 minutes. There was no recovery of nerve function during the two hours following pressure release. According to the light and electron microscopical findings compression at this pressure level induced severe damage of nerve fibres (figs 7 and 8), which may explain the rapid deterioration and the absence of functional recovery. Another factor which probably contributed to the impairment of nerve function when the nerves had been compressed at 200 and $400 \mathrm{mmHg}$, is the development of endoneurial oedema, which is induced in our model when nerves are compressed at these pressure levels. ${ }^{13}$

Late effects of compression on nerve function and structure

The nerves which had been compressed at 50 $\mathrm{mmHg}$ for two hours showed no, or only minimal, late reduction of conduction velocity compared to the controls (table 1). There were, however, slight morphological signs of nerve fibre damage (table 4), indicating that a peripheral nerve may be subjected to moderate compression, without persistent functional deterioration, although such a procedure may induce "subliminal" morphological signs of nerve fibre injury.

Compression at 200 and $400 \mathrm{mmHg}$ for two hours induced functional and structural disturbances of varying degree which persisted at least three weeks. The damage and dysfunction was generally most pronounced in the nerves which had been compressed at $400 \mathrm{mmHg}$ (tables 3 and 6). Our observation of a reduced conduction velocity in nerves recovering from compression is in good accordance with findings by Mayer and Denny-Brown ${ }^{25}$ and Fowler et al. ${ }^{11}$ In our experiments, the nerves which had been compressed at $200 \mathrm{mmHg}$ for two hours exhibited a localised reduction of conduction velocity only over the compressed segment (table 2 and fig 5a). This indicates that some of the fastest conducting fibres of the nerve trunk were either conducting at reduced velocity or blocked at the level of compression. The results of the functional tests also indicate that a certain number of functioning fast conducting nerve fibres were still present in the nerve distal to the compressed segment (table 2). This is in good agreement with the morphological picture, which demonstrated that there were many large fibres preserved in this segment of the nerve (table 5).

In the nerves which had been compressed at $400 \mathrm{mmHg}$ for two hours, the conduction velocity was reduced both at the level of compression and distal to this level (table 3, fig 5b), a finding which indicates a significant Wallerian degeneration of fast conducting, large diameter fibres. There was also in these cases a close correlation between the functional and the structural findings (tables 3 and 6). One important cause of prolonged impairment of nerve function after acute compression is the structural damage to the nerve 
fibres (figs 7 and 8). Compression at 200 and 400 $\mathrm{mmHg}$ for two hours in our model induces, however, also endoneurial oedema, by increasing the permeability of the endoneurial capillaries. ${ }^{13}$ This oedema might affect nerve function for example directly, by altering the ionic balance of the nerve fibres ${ }^{9}$ or indirectly, by increasing the endoneurial pressure ${ }^{26}{ }^{27}$ thereby possibly causing collapse of endoneurial capillaries. Late impairment of intraneural microcirculation in a compressed segment of a nerve has been found in our model three to seven days after compression at $400 \mathrm{mmHg}$ for two hours. ${ }^{12}$ Such persistent ischaemia is likely to contribute to the functional disturbances, which were pronounced in these cases (table 3).

Functional tests have demonstrated that the block of conduction induced by acute compression is most prominent at the margins of the compressed segment. ${ }^{6}{ }^{28}$ Edwards and Cattell ${ }^{29}$ showed that the deformation of the nerve trunk caused by local compression was most severe at the boundaries of the compressed segment, and this is the level where nerve fibre damage ${ }^{10}$ and intraneural microvascular injury ${ }^{13}$ have been shown to be maximal. It thus seems as if the deformation of the nerve at the edges of the compressed segment with subsequent damage to nerve fibres and intraneural blood vessels at these levels, is the most critical factor for development of functional deterioration after nerve compression. In our chronic experiments, the nerve fibre damage was not confined only to the cuff edge zones (tables 5 and 6). One explanation to this could be that the direct compression of the nerves caused considerable axonal degeneration which, even if induced at the edge zones, would also affect more distal parts of the nerve.

In experiments by Fowler et $a^{11}$ in which tourniquets were inflated to high pressure $(1000$ $\mathrm{mmHg}$ ) around the knee of baboons for one to three hours, this procedure induced a neurapraxic lesion of the peroneal nerve. Thus, 400 $\mathrm{mmHg}$ applied directly to the nerves in our experiments induced degeneration of a significant number of nerve fibres, while $1000 \mathrm{mmHg}$ applied indirectly by a tourniquet induced no or only minimal Wallerian degeneration. These two different methods of compressing nerves probably induce different patterns of mechanical nerve tissue deformation. This might explain why the extent of nerve fibre damage in the two studies seems to be contradictory with a more severe damage at lower pressure. It is thus of importance to consider, not only pressure level and compression time, but also the mode of pressure applica- tion in connection with nerve compression lesions.

This work was supported by grants from the Swedish Medical Research Council (project no 5188); the Faculty of Medicine, University of Göteborg; the Göteborg Medical Society; the Swedish Work Environment Fund.

\section{References}

1 Moldaver J. Tourniquet paralysis syndrome. Arch Surg 1954; 68:136-44.

2 Rudge P. Tourniquet paralysis with prolonged conduction block; an electrophysiological study. J Bone Joint Surg 1974; 56B:716-20.

3 Mitchell SW. Injuries of Nerves and Their Consequences. Philadelphia: Lippincott JB, 1872 (cited by Bentley and Schlapp 1943).

4 Meek WJ, Leaper WE. The effect of pressure on conductivity of nerve and muscle. Amer $J$ Physiol 1911; 27:308-22.

5 Gasser HS. Erlanger J. The role of fibre size in the establishment of a nerve block by pressure and cocain. Amer J Physiol 1929; 88:581-91.

6 Bentley FH, Schlapp W. The effects of pressure on the conduction in peripheral nerve. J Physiology (Lond.) 1943; 102:72-82.

7 Denny-Brown D, Brenner C. Paralysis of nerve induced by direct pressure and by tourniquet. Arch Neurol Psych 1949; 51:1-26.

8 Denny-Brown $\mathrm{D}$, Brenner C. Lesion in peripheral nerve resulting from compression by spring clip. Arch Neurol Psych 1944; 52:1-19.

9 Lundborg G. Ischemic nerve injury. Experimental studies on intraneural microvascular pathophysiology and nerve function in a limb subjected to temporary circulatory arrest. Scand J Plast Reconstr Surg 1970; Suppl. 6.

10 Ochoa J, Fowler TJ, Gilliatt RW. Anatomical changes in peripheral nerves compressed by a pneumatic tourniquet. J Anat 1972; 113:3, 433-55.

11 Fowler RJ, Danta G, Gilliatt RW. Recovery of nerve conduction after a pneumatic tourniquet: Observations on the hind-limb of the baboon. J Neurol Neurosurg Psychiatry 1972; 35:638-47.

12 Rydevik B, Lundborg G, Bagge U. Effects of graded compression on intraneural blood flow (in press). J Hand Surg 1980.

13 Rydevik B, Lundborg G. Permeability of intraneural microvessels and perineurium following acute, graded experimental nerve compression. Scand J Plast Reconstr Surg 1977; 11:179-87.

14 Rydevik B, McLean WG, Sjöstrand J, Lundborg G. Blockage of axonal transport induced by acute, graded compression of the rabbit vagus nerve. (In press). J Neurol Neurosurg Psychiatry 1980. 
15 Karnovsky MJ. A formaldehyde-glutaraldehyde fixation of high osmolarity for use in electron microscopy. J Cell Biol 1965; 27:137a.

16 Richardsson KC, Jarett L, Finke EH. Embedding in epoxy resins for ultrathin sectioning in electron microscopy. Stain Technol 1960; 35: 313-23.

17 Ramón Y Cajal S. Degeneration and regeneration of the nervous system. Vol I. London: Oxford University Press, 1928.

18 Ochs S. Energy metabolism and supply of $\sim \mathrm{P}$ to the fast axoplasmic transport mechanism in nerve. Fed. Proc 1974; 33:1049-58.

19 Leone J, Ochs S. Anoxic block and recovery of axoplasmic transport and electrical activity of nerve. J Neurobiol 1978; 9:229-45.

20 Sunderland $\mathrm{S}$. Nerves and Nerve Injuries. Edinburgh and London: Livingstone $\mathrm{E}$ and $\mathrm{S}$. 2nd ed. 1978.

21 Clark D, Hughes J, Gasser HS. Afferent function in the group of nerve fibers of slowest conduction velocity. Amer J Physiol 1935; 114: 69-76.

22 Gasser HS. Conduction in nerves in relation to fiber types. Proc Ass Res Nerv Ment Dis $1935 ; 15: 35-59$.
23 MacGregor RJ, Sharpless SK, Luttges MW. A pressure vessel model for nerve compression. J Neurol Sci 1975; 24:299-304.

24 Revenäs B, Lindholm C-E. Pressure and volume changes in tracheal tube cuffs during anaesthesia. Acta Anaesth Scand 1976; 20: 321-6.

25 Mayer RF, Denny-Brown D. Conduction velocity in peripheral nerve during experimental demyelination in the cat. Neurology 1964; 14:714-26.

26 Low PA, Dyck PJ. Increased endoneurial fluid, pressure in experimental lead neuropathy. Science 1977; 269:427-8.

27 Powell HS, Meyers RR. Zweifach BW, Lampert PW. Endoneurial pressure in hexachlorophene neuropathy. Acta Neuropathol (Berl) 1978; 41:139-44.

28 Gilliatt RW, McDonald WI, Rudge P. The site of conduction block in peripheral nerves compressed by a pneumatic tourniquet. J Physiol (Lond) 1974; 238:31P.

29 Edwards DJ, Cattell MK. Further observations on the decrement in nerve conduction. Amer $J$ Physiol 1928; 87:359-67. 